\title{
New European collaborations
}

\section{The European Science Foundation has an enviable record in breaking European national chauvinism, but is now having to turn away good proposals. It needs a much bigger budget.}

AMONG grant-making agencies, the European Science Foundation enjoys the distinction of spending the world's most weightily considered research budget. Last week's general assembly, which in the end approved a budget for 1988 amounting to FF 11 million, just over $£ 1$ million, brought to this inaccessible city the presidents of half a dozen European national academies and research councils together with personages almost as exalted representing other nationa research councils and international organizations.

For people who are responsible for annual budgets several hundreds of times larger (those of the West German MaxPlanck Gesellschaft or the French Centre National de la Recherche Scientifique, for example), the case for spending two days travelling to and from Strasbourg cannot simply be the food. The truth is that the European Science Foundation (ESF) seems to be every participant's concept of what constitutes a good idea. The budget may be small, but is it not the future pattern of European research in microcosm?

But ESF is neither a research organization, with laboratories or research employees of its own, nor a foundation, with money of its own to spend. Instead, it is a membership organization whose members are national academies and research councils and whose dues constitute ESF's sole source of funds. A further complication is that the 49 member organizations come from a set of 18 European countries that seems not to coincide with any other - as well as the members of the European Communities, for example, there are three Scandinavian countries, Austria, Switzerland and Yugoslavia.

ESF has several ways of working. Some of what it does is hortatory, as when it produces documents such as that nearly ten years ago regretting the neglect of space science by the European Space Agency. Sometimes it functions as a midwife, as when it set out to make the case for a European synchrotron radiation source (and then found itself at the centre of a squabble about the siting of the machine, which is now being built at Grenoble). In these roles, which are supported from the general budget, the foundation is evidently a convenient stalkinghorse for at least some of its members: it may be able to say things that would get individual members into trouble.

Last week's general assembly approved an extension of the European Geotraverse project until 1990, partly because those who have collected data from the various sections of the traverse believe that time could usefully now be spent on the coordinated interpretation of the data but also because the European Commission has just made a grant of 1.2 million ECU (European Currency Units, about $£ 800,000)$ to support a continuation of data-gathering in the Iberian peninsula.

Although ESF's direct spending on this project (from the funds contributed by members electing to take part) is relatively modest, covering the cost of a project officer based in Zurich and various workshops and planning meetings, its members in their role as national research councils have spent many times as much on research support for the groups that have carried out the work. Some of those who travel to Strasbourg say that their justification is the potentially high leverage of the foundation's small budget.

Additional activities will continue to be added. Last week, the assembly agreed to the first phase of a project, urged by $\mathrm{Dr}$ Peter Fricker, secretary-general of the Swiss National Science Foundation, to compile a coordinated palaeoclimatology of Europe based on physical, archeological and historical records; a scheme for a coordinated study of the emergence in Europe of the modern nation state (dated at the thirteenth century); and a scheme labelled "environmental toxicology" which began life as a wish by member organizations for an objective basis on which their governments might frame environmental legislation, but which had some people last week sucking their teeth because of its imprecision.

But this year's new flavour is called "networks", and springs directly from the recognition that, if the enduring value of what the foundation does is to demonstrate to researchers the value of collaboration, the simplest way of maximizing this benefit may simply be to bring people together to discuss common problems.

Sir Arnold Burgen, until recently foreign secretary of the Royal Society, has been the chairman of a committee weeding out requests for help with the formation of networks in fields as different as "polar science" and "Iongitudinal studies of development". Evidently, ESF has been embarrassed by the good proposals which have come its way. Only nine of thirty or so have been accepted so far.
Some of the networks seem to have fired the enthusiasm of their participants. Thus the West German participants in the polar science network are eagerly planning to carry several fellow-members on a largely biological exploration of the Antarctic pack-ice next Antarctic spring and summer, using substantial resources that never touch ESF's hands in the process. Much the same is true of the network of "molecular neurobiology of mental illness", which is really a hunt for European families likely, on psychiatric grounds, to provide genetic polymorphisms likely to be technically informative of the genetic basis of psychiatric illness.

The success of the networks is both an embarrassment and a pointer to ESF's general difficulties. Burgen's committee has been aiming to find four new networks a year. Its strategy is to nurse each of them through the first two years (Phase I) and then to persuade member research councils to keep them going longer. The direct cost of the first two years is estimated at FF 550,000. By "passing round the hat", ESF has collected a seed-fund of nearly FF 10 million, but most of that is already committed. That is why a Norwegian delegate at last week's meeting pleaded for restraint - perhaps two and not four networks a year. Evidently, the substrates are beginning to fear what the catalysts may provoke financially.

But if ESF has struck a vein of European collaboration that excites the respect of working researchers, should not the argument be turned around? If an activity which is generally welcomed, not merely by the participants but by organizations such as the European Commission, would it not make sense to increase the funds available? And should not ESF have enough cash to be able to hold what are exploratory meetings such as those planned for its environmental toxicology project? The general opinion is that ESF's budget should be ten times bigger than it is.

Where could the money come from? National research councils fear that more for ESF would mean less for them, but there is a case that governments should contribute something through their foreign offices. So should the European Commission. Luckily, for ESF, the networks should so quickly make ESF much better known that there may soon be an international lobby of researchers for the continuation and growth of its good works.
John Maddox 